\title{
Ultrasonic Measurement of Kidney Length in Nepalese People
}

\section{Rajendra Prasad Koirala, Sunil Pradhan and \\ Shesh Kanta Aryal}

Journal of Nepal Physical Society

Volume 4, Issue 1, February 2017

ISSN : 2392-473X

Editors:

Dr. Gopi Chandra Kaphle

Dr. Devendra Adhikari

Mr. Deependra Parajuli

JNPS, 4 (1), 49-53 (2017)

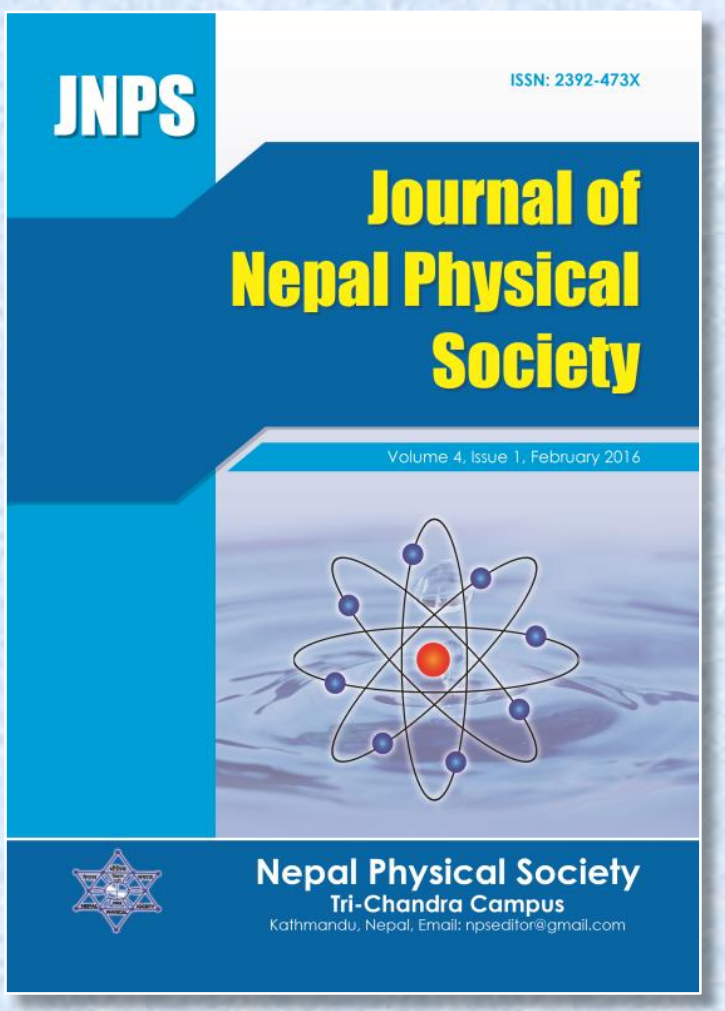

Published by:

Nepal Physical Society

P.O. Box : 2934

Tri-Chandra Campus

Kathmandu, Nepal

Email: npseditor@gmail.com 


\title{
Ultrasonic Measurement of Kidney Length in Nepalese People
}

\author{
Rajendra Prasad Koirala ${ }^{1, *}$, Sunil Pradhan ${ }^{2}$, Shesh Kanta Aryal ${ }^{1}$ \\ ${ }^{I}$ Central Department of Physics, Tribhuvan University, Kirtipur, Nepal \\ ${ }^{2}$ Tribhuvan University Teaching Hospital, Maharajgung, Kathmandu, Nepal \\ *Corresponding Email: rpkoirala@tucdp.edu.np
}

\begin{abstract}
Ultrasonography (USG) is a major modality to determine the dimension of internal body parts and foreign materials that enters into the tissue. This modality can measure the accurate value of the size of organs because it has no magnification property. This measurement based on the sound pulse to travel to the object and the echo to return back. In the present study, the ultrasonographic kidney length is determined in individuals without known renal disease. The experiment is done 504 patients (214 males and 290 females) who came to Tribhuvan University Teaching Hospital (TUTH) from May 2001 to August 2001. The average kidney size of Nepalese people was found $(9.48 \pm 0.96) \mathrm{cm}$. The kidney length was found maximum in the age range around 40 years and observed approximately not changing significantly up to the age of 60 and decreasing from the age range 60 years. Moreover, average kidney size of male is found to be greater than the female of same age group.
\end{abstract}

Keywords: Ultrasonography, Propagation, Transducer, Renal size.

\section{INTRODUCTION}

Ultrasonography, one of the major tools of modern medicine, is a technology to view the organs inside the human body. This technology uses sound waves to create images of structures which lie deep within the body. Ultrasound is an effective and safe way for doctors to examine what's going on inside the body (Buchholz et al., 2000). Diagnostic ultrasound has found widespread applications in the measurement of internal body size and mass as well as the field of obstetrics and gynecology because of the absence of any known hazard to the fetus (Raza et al., 2011). Ultrasonography is basically a reliable, non-invading and relatively inexpensive method of measurement of kidney size. Due to its noninvading behavior, it is also used to cardiac abnormalities (Schmidt et al., 2004; Oliv et al., 2012). In the present study, ultrasound is employed to measure the length of kidneys in Nepalese people without known renal disease.

The kidney length measurement is very important in clinical diagnosis and treatment of renal diseases and in kidney transplantation (Emamiam et al., 1993). Many studies have shown that in various diseases kidney size changes, which is probably due to inflammation resulting from infections and by concentration of water and minerals. Diabetes can also increase the size of kidney and many other chronic diseases can decrease the size of kidney (Mogensen et al., 1973; Mohammed et al., 2016, Mocroft et al., 2016). Moreover, the dating of pregnancy in second and third trimesters is very reliable from ultrasound parameters. It has been found that fetal kidney length is strongly correlated with gestation age in late trimesters (Khare et al., 2015; Kumar et al., 2015).

Diagnostic ultrasound technology works in the echo produced by internal body tissue, using the mechanical wave of high frequency range $20 \mathrm{kHz}$ and above. The native kidneys are based imaged with a 2-5 $\mathrm{MHz}$ transducer, dependent on the patient's body habitus and the depth of the kidney (Hertzberg et al., 2016; Khan, 2012). The renal size correlates best with height and mass of individual person and size decreases with age because of parenchymal reduction. Many researchers have found that the length of right kidney is shorter than the left kidney; possibly it happens due to the relatively larger potential space for left renal growth (Raza et al., 2011; Schmidt et al., 2004; Barton et al., 2000; Cheong et al., 2007; Miletic et al., 1998; Zerin and Blane, 1994). The growth of right kidney might be inhibited by liver. The parenchymal volume of the right kidney is smaller than that of the left kidney (Carrico and Zerin, 1996; Rumach et al., 2011). The measurement of kidney size may be varied due to the position of 
patient, examiner's experience and equipment used (Carrico and Zerin, 1996).

Intensity of ultrasound echo depends on the acoustic impedance of the tissue. The visibility image of reflecting tissue is related with reflection coefficient and transmission coefficient of ultrasound from the interface of targeted tissue. The value of high reflection coefficient of ultrasound from the interface of two connecting tissues play very important role in visualizing the internal body organs. The propagation speed and precise measure of time of ultrasound employ to determine the size and depth of body organs from the body surface (Rumach et al., 2011). The amount of reflected energy is expressed in terms reflection coefficient $\alpha_{\mathrm{r}}$ of Ultrasound. Mathematically, the reflection coefficient $\alpha_{r}$ is, $\alpha_{r}=\left(\frac{Z_{1}-Z_{2}}{Z_{1}+Z_{2}}\right)^{2}$. And the fraction of the incident energy is expressed in terms of transmission coefficient of ultrasound which is, $\alpha_{t}=\frac{4 Z_{1} Z_{2}}{\left(Z_{1}+Z_{2}\right)^{2}}$, Where $Z_{1}$ and $Z_{2}$ are the sound impedance of the two media $(Z=v \rho)$ and $v$ is speed of ultrasound and $\rho$ is the density of the medium through which the wave is propagated. High reflection coefficient shows that most of the incident energy is reflected from the surface of the tissue. This phenomenon obscures the visibility of the materials inside that tissue (Hendee and Ritenour, 2002).

\section{MATERIALS AND METHOD}

\section{a. Material:}

Toshiba nemico containing computer monitor, Central Processing Unit (CPU) and transducer were used to measure normal kidney length of Nepalese people.

Ultrasound transducer links the computer system with the human body. The transducer generates the ultrasound and sends to the internal body parts. The ultrasound travels to the tissues and gets reflected from the boundary of organs which is finally reflected to the transducer again in the form of sound echoes. The echoes carry the message from the internal organs and relay the information of body structure to the computer Central Processing Unit (CPU), which finally displays the structure of internal organ on the monitor screen.

\section{b. Measurement steps:}

Patients were called in fasting condition for a minimum of 6 hours to prevent bowel gas obscuring the kidney. They were kept in supine position asked for a relax. Kidney is mobile and its position depends on the position of body, in supine position, the superior pole of the left kidney is at the level of the twelfth thoracic vertebra and the interior pole is at the level of the third lumber vertebra (Glodny et al., 2009). The sonographic gel, called coupling agent, was applied to the traducer so that the air between transducer and skin was removed. The Patient was asked to take a deep breath and hold. This causes kidney to move down thus help in visualizing the upper pole. Coronal images of kidneys were taken (first right side and the left side) by placing the transducer in flank. Most of the time only supine position can be adequate to visualize the kidneys completely; hence changing the position oblique and lateral decubites helps in optimizing the visualization, specialization, specially in left side, where there is no acoustic window as compared to right side where liver act as acoustic window. After finding best image in coronal plane, image was freezed and craniocaudal measurement of the kidney was done. Similar method was applied to the left kidney. Some pictures are mentioned in the figure 1 to show the procedure for ultrasonic measurement of kidney length.
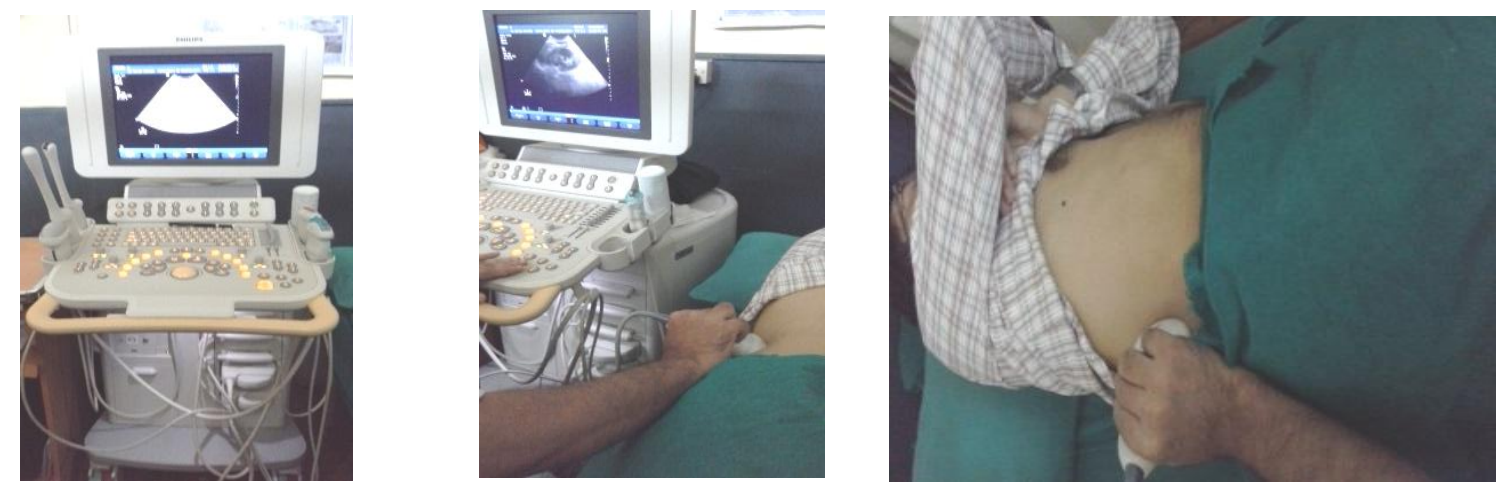

Fig.1. Pictures showing the ultrasonic measurement of kidney length. 


\section{RESULTS AND DISCUSSION}

The renal length of 214 male and 290 female were observed and average kindney length was compared in accordance with sex, side and age. This study of renal length is very useful for routine evaluations monitoring of urological and nephrological diseases. The table for the kidney length of individuals without known renal diseases are listed in the table 1 and table 2 . The experiment was conducted only in Nepalese people of all age group who came to Tribhuvan University Teaching Hospital (TUTH), Maharajgung. The tabulation is performed in the class interval of $1 \mathrm{~cm}$ range.

Table 1. The table contains the number of male in accordance with renal size and age group. The column in the table contains number of people in accordance of age group in terms of class range of 20 years and the row in the table contains the length of kidney in terms of class interval class range of $1 \mathrm{~cm}$.

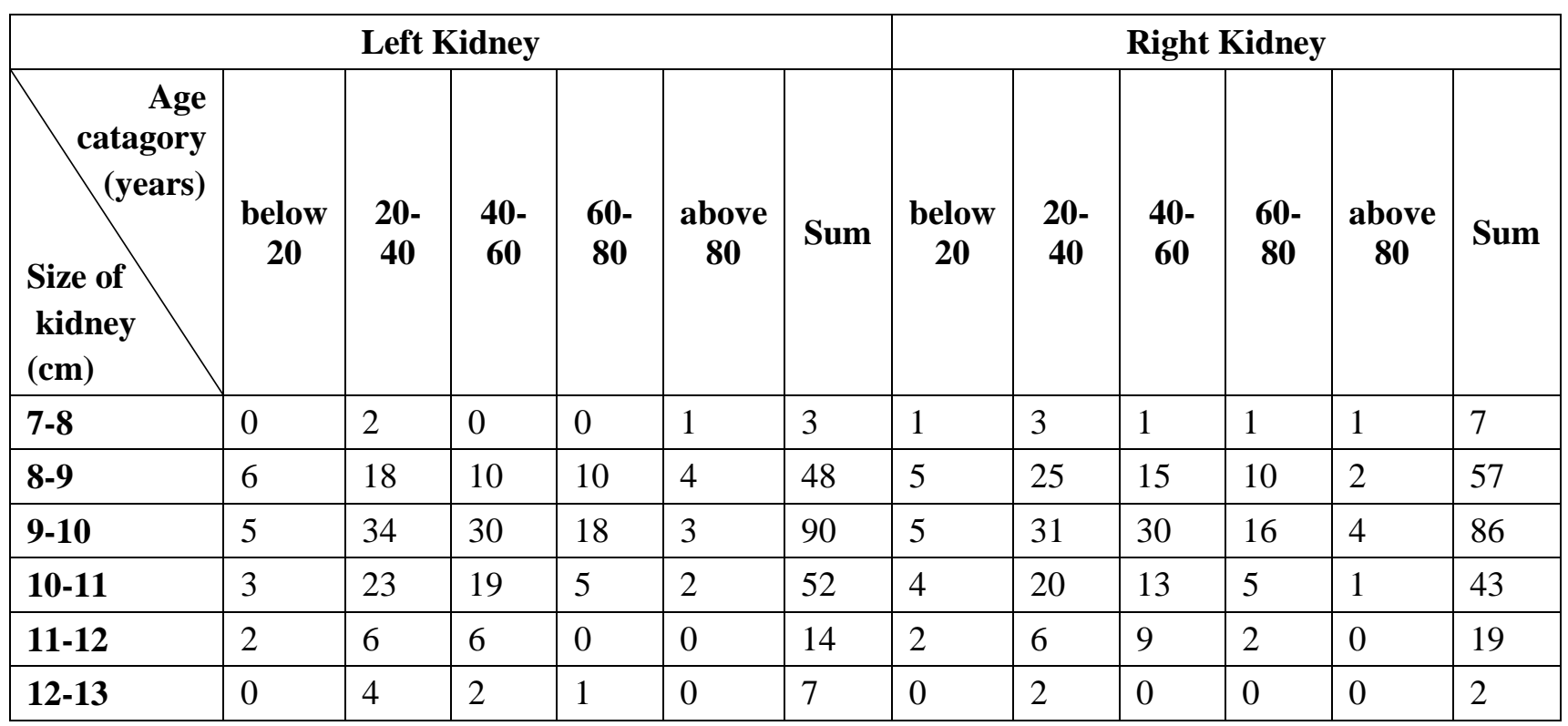

Table 2. The table contains the number of female in accordance with renal size and age group. The column in the table contains number of people in accordance of age group in terms of class range of 20 years and the row in the table contains the length of kidney in terms of class interval class range of $1 \mathrm{~cm}$.

\begin{tabular}{|l|l|l|l|l|l|l|l|l|l|l|l|l|}
\hline \multicolumn{1}{|c|}{ Left Kidney } \\
$\begin{array}{r}\text { Category } \\
\text { (years) }\end{array}$ \\
$\begin{array}{l}\text { Size of } \\
\text { Kidney } \\
(\mathbf{c m})\end{array}$
\end{tabular}


The graph to study the number of people with respect to the average kidney size of sample population is presented in graph as shown in figure 2. In the graph, $\mathrm{x}$-axis contains the average kidney size and $y$-axis contains the number of people for the corresponding kidney length. The graph shows that the kidney size of maximum nepalese population lies between $9.0 \mathrm{~cm}$ to $10.0 \mathrm{~cm}$.

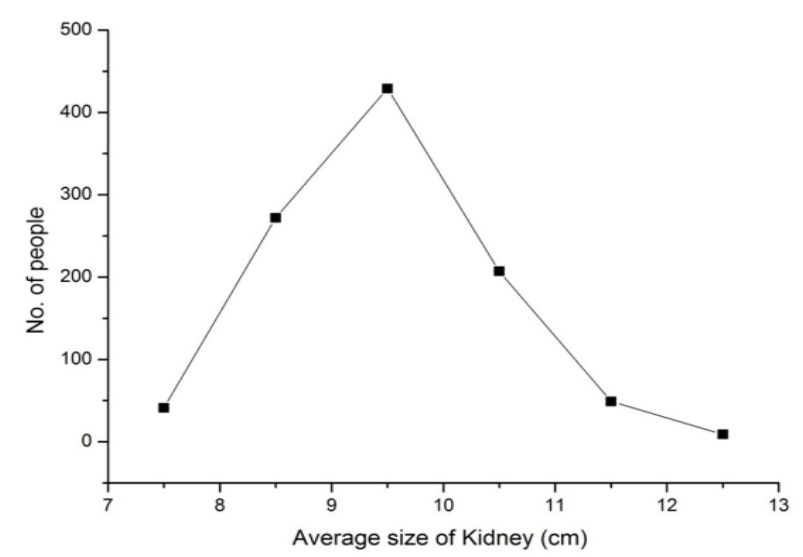

Fig.2. Number of people with respect to the average kidney size of sample population.

The comparison of kidney size of male, female and overall population for different age group is presented in graph as shown in figure 3. In the graph, $\mathrm{x}$-axis contains the age category and $\mathrm{y}$-axis contains the average kidney length for the corresponding age catagory. On analyzing the graph, the average kidney length of male was observed greater than that of female for all age groups. Moreover, the kidney length was observed increasing with age upto the middle age (about 40 years) in both male and female. However, kidney length of female was found decreasing in the earlier age than the male.

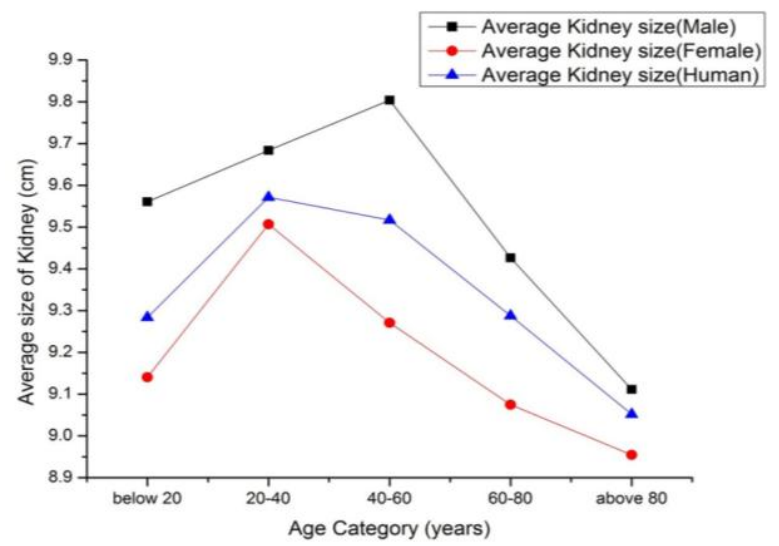

Fig. 3. Comparison of kidney size of male, female and overall population for different age group.
The histogram drawn in Figure 4, in which $\mathrm{x}$-axis contains the age categories in class range of 20 years each and y-axis, contains the average kidney length for the corresponding age categories. The histogram shows that the kidney size is observed increasing with age upto the middle age (about 40 years) and is not found changing significantly upto the age of 60 years, then found decreasing significantly. The length of kidney of old people, specially age greater than 80 year was found smaller than the child below the age of 20 year.

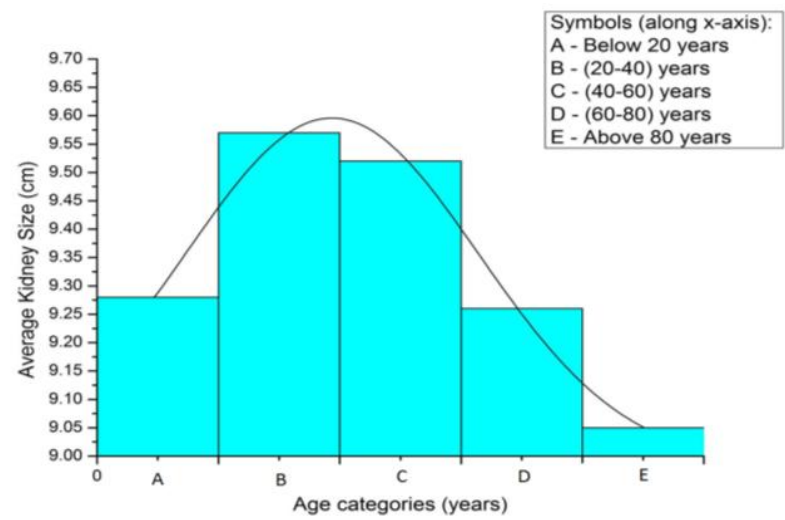

Fig. 4. A histogram showing the variation of average kidney length of Nepalese people in accordance of age categories.

From statistical analysis, the length of kidney was also calculated in terms of side. The length of left kidney was found greater than the length of right kidney. The average length of left kidney was observed $9.58 \mathrm{~cm}$ and the average length of right kidney was observed $9.38 \mathrm{~cm}$. the average kidney length of Nepalese population was found $9.48 \mathrm{~cm}$.

\section{CONCLUSION}

The mean renal lengths of Nepalese people are found (mean \pm S.D. $=9.48 \pm 0.96 \mathrm{~cm}$ ). The mean renal length of male is observed greater than the female. In accordance with side, left kidney is larger than right kidney. Kidney length is found dependent with the age, increasing up to the middle age up to age of 40 years and then decreasing in the older age, specifically renal length is found significantly decreasing after the age of 60 , however the length is observed decreasing in the earlier age in female than the male. In comparison with the European and American people (Emamian et al., 1993), the length of kidney in Nepalese people is significantly smaller. Even the size is smaller than the Indian and Pakistani people (Buchholz et al., 2000). 


\section{ACKNOWLEDGEMENT}

All the medical officers of Tribhuvan university teaching hospital, Maharajgung are thankful to provide the space and continuous cooperation in the measurement of kidney length to carry out this research project.

\section{REFERENCES}

Barton, E. N.; West, W. M.; Sargeant, L. A.; Lindo, J. F., and Theonunekwu, N. C. (2000). A sonographic study of kidney dimensions in a sample of healthy Jamaicans. The West Indian medical journal, 49(2): 154-157.

Buchholz, N. P.; Abbas, F.; Biyabani, S. R.; Javed, Q.; Talati, J.; Afzal, M., and Rizvi, I. (2000). Ultrasonographic renal size in individuals without known renal disease. Journal of the Pakistan Medical Association, 96(1): 12.

Carrico, C. W., and Zerin, J. M. (1996). Sonographic measurement of renal length in children: does the position of the patient matter?. Pediatric radiology, 26(8): 553-555.

Cheong, B.; Muthupillai, R.; Rubin, M. F., and Flamm, S. D. (2007). Normal values for renal length and volume as measured by magnetic resonance imaging. Clinical Journal of the American Society of Nephrology, 2(1): 38-45.

Emamian, S. A.; Nielsen, M. B.; Pedersen, J. F., and Ytte, L. (1993). Kidney dimensions at sonography: correlation with age, sex, and habitus in 665 adult volunteers. AJR. American journal of roentgenology, 160(1): 83-86.

Glodny, B.; Unterholzner, V.; Taferner, B.; Hofmann, K. J.; Rehder, P.; Strasak, A., and Petersen, J. (2009). Normal kidney size and its influencing factors-a 64-slice MDCT study of 1.040 asymptomatic patients. BMC urology, 9(1): 1 .

Hendee, W. R., and Ritenour E. R. (2002). Medical Imaging Physics, John willy and sons, USA, Fourth edition.

Hertzberg, B. S., and Middleton W. D. (2016). Ultrasound: The requisites, Elesevier, inc, All right, USA, Third edition.

Khan, F. M. (2012). The physics of Radiation Therapy, Williams and Wilkins, USA, Fourth edition.

Khare, S.; Chatterjee, M.; Roul, B., and Mandle, H. (2015). Estimation of Gestational Age by Real Time Ultrasonography (Biparietal Diameter and Head Circumference) to Estimate the Fetal
Morphometry in IInd and IIIrd Trimester. Indian Journal of Anatomy, 4(3): 123.

Kumar, K.; Beg, M. R.; Babu, C. S., and Shrivastava, R. K. (2015). Estimation of Fetal Gestational Age in Second and Third Trimesters from Ultrasonographic Measurements of Different Fetal Biometric Parameters. Indian Journal of Clinical Anatomy and Physiology, 2(3): 111-116.

Miletic D.; Fuckar Z.; Sustic, A.; Mozetic, V.; Stimac, D., and Zauhar, G. (1998). Sonographic measurement of absolute and relative renal length in adults. Journal of clinical ultrasound, 26(4): 185-189.

Mocroft, A.; Lundgren, J. D.; Ross, M.; Fux, C. A.; Reiss, P.; Moranne, O. et al. (2016). Cumulative and current exposure to potentially nephrotoxic antiretrovirals and development of chronic kidney disease in HIV-positive individuals with a normal baseline estimated glomerular filtration rate: a prospective international cohort study. The Lancet HIV, 3(1): e23-e32.

Mogensen, C. E., and Andersen, M. J. F. (1973). Increased kidney size and glomerular filtration rate in early juvenile diabetes. Diabetes, 22(9): 706-712.

Mohammed, A. A. M. (2016). Evaluation of Renal Changes in Diabetic and Hypertensive Patients using Ultrasound and Laboratory Findings (Doctoral dissertation, Sudan University of Science and Technology).

Otiv, A. S.; Mehta, K.; Ali, U., and Nadkarni, M. (2012). Sonographic measurement of renal size in normal Indian children. Indian pediatrics, 49(7): 533-536.

Raza, M.; Hameed, A., and Khan, M. I. (2011). Ultrasonographic assessment of renal size and its correlation with body mass index in adults without known renal disease. $J$ Ayub Med Coll Abbottabad, 23(3): 64-68.

Rumach, C. M.; Wilson S. R.; Charboneau, J. W., and Levine, D. (2011), Diagnostic Ultrasound, Elesevier, Inc, USA, Fourth edition.

Schmidt, I. M.; Main, K. M.; Damgaard, I. N.; Mau, C.; Haavisto, A. M.; Chellakooty, M. et al. (2004). Kidney growth in 717 healthy children aged 0-18 months: a longitudinal cohort study. Pediatric Nephrology, 19(9): 992-1003.

Zerin, J. M., and Blane, C. E. (1994). Sonographic assessment of renal length in children: a reappraisal. Pediatric radiology, 24(2): 101-106. 